\title{
Simulated and experimental analysis of laser beam energy profiles to improve efficiency in wire-fed laser deposition
}

\author{
Nicholas Goffin ${ }^{1}$ (D) - John R. Tyrer ${ }^{1}$ (D) - Lewis C. R. Jones ${ }^{1}$ (D) $\cdot$ Rebecca L. Higginson ${ }^{2}$ (D)
}

Received: 6 November 2020 / Accepted: 29 March 2021 / Published online: 20 April 2021

(C) The Author(s) 2021

\begin{abstract}
Laser cladding is a well-established technique, with the majority of prior numerical modelling work focused on delivery and melt pool behaviour of powder-based processes. This research presents new investigations into optimised laser beam shaping for the unique characteristics of wire-based processes, where direct substrate heating, as well as heat transfer between the wire and substrate, is important. The value of this subject is the improved deposition rates and dense metallic structures that can be achieved by wire-based deposition processes compared to powder-based material delivery. The within-wire temperature distribution (AISI 316 stainless steel), the heat transfer and direct heating of the substrate (mild steel) are modelled via heat transfer simulations, with three laser beam irradiance distributions. This analysis identified the removal of localised high-temperature regions typically associated to standard Gaussian distributions, and the improved substrate heating that a uniform square beam profile can provide. Experiments using pre-placed wire and a $1.2 \mathrm{~kW} \mathrm{CO}_{2}$ laser were analysed using cross-sectional optical microscopy to provide model validation and evidence of improved wire-substrate wetting, while maintaining favourable austenitic metallurgy in the clad material. A key finding of this work is a reduction, from 480 to $190 \mathrm{~W} / \mathrm{mm}^{2}$, in the required irradiance for effective melt pool formation when changing from a Gaussian distribution to a uniform square distribution. This also provided a $50 \%$ reduction in total energy. The potential improvements to energy efficiency, cost reductions and sustainability improvements are recognised and discussed.
\end{abstract}

Keywords Directed energy deposition · Holographic optical elements $\cdot$ Heat transfer $\cdot$ Simulation $\cdot$ Energy efficiency $\cdot$ Resource efficiency

\section{Introduction}

A widely utilised technique for depositing a metallic clad material onto a metallic substrate is Laser Directed Energy Deposition (DED), also known as Laser Cladding or Laser Deposition, for such purposes as surface protection [1], surface repair [2] and additive manufacturing [3].

While laser cladding processes date back to the 1970s, there have been many recent developments in the simulation

Nicholas Goffin

n.goffin@lboro.ac.uk

1 Wolfson School of Mechanical, Electrical and Manufacturing Engineering, Loughborough University, Loughborough LE11 3TU, UK

2 Department of Materials, Loughborough University, Loughborough LE11 3TU, UK and experimentation of this technology associated with the growth in DED additive manufacturing processes. DED can relate to both powder and wire-fed material deposition processes with laser heating [4]. A valuable application of DED is the depositing of high-performance superalloys together in manufactured parts. Recent work in DED manufacturing with powder feed has been carried out by Alizadeh-Sh et al. [5] using In718 powder on A-286 steel substrate. In this work, focus has been on the prediction, control and characterisation of material properties, since Inconel can demonstrate vulnerabilities to defects such as solidification cracking [6].

\subsection{Laser thermal modelling}

Research into the simulation of laser surface treatment began with welding, with Rosenthal's models in the 1930s [7]. This model was computationally relatively simple, and did not account for metal flow or phase changes [8]. Other welding simulations were created by Limmaneevichitr and Kou [9], 
who made a study of Marangoni convection with a defocussed $\mathrm{CO}_{2}$ laser beam, showing this as responsible for the vast majority of melt pool thermal transport.

\subsection{Modelling of laser DED processes}

In laser DED, a Finite Element Model (FEM) was created by Picasso and Hoadley (1994) [10], which modelled melt pool fluid flow. Kim and Peng [11] carried out additional studies of melt pool shape and dilution. This analysis showed that it was necessary for laser parameters to adapt to account for increasing temperature throughout the process. A powder-fed laser DED model was also created, 2dimensional (both width and dilution), using a $3 \times 3 \mathrm{~mm}$ uniform beam profile [12]. ABAQUS was used by Zhao et al. [13] to model the dilution behaviour of laser DED processes, which included a longitudinal dimension. Cho et al. [14] used ABAQUS to create a 3D heat transfer model, investigating latent heat (heat absorbed during a solid-liquid phase change) which usually neglected for simplicity. This inclusion both lowered the peak predicted temperature and shrank the melt pool, less strongly for a stationary beam than for a moving one. Hot-wire laser cladding modelling was carried out by Wei et al. [15], using a multi-phase model. Again, however, this was focused on melt pool dynamics and Marangoni flow, not on pre-melt heating.

Investigations have also been carried out to investigate laser beam control. Toyserkani et al. created an FEM model [16] to simulate pulse-shaping effects on blownpowder DED. Tseng and Aoh [17] created studies on pre-placed powder, with multiple modes, which included $\mathrm{TEM}_{00}$ (Gaussian), $\mathrm{TEM}_{01}$ (ring) and $\mathrm{TEM}_{33}(4 \times 4$ dot array). Higher beam modes returned increased melt pool shape uniformity, which was experimentally verified. Improvements to Additive Manufacturing (AM) metallurgy were also achieved by Roehling et al. [18] through elliptical beam profile generation.

Another major challenge for AM is residual stress, which can cause high levels of build failures. Given the low productivity and high cost of the process, much effort has been directed at simulating and predicting these stresses, to avoid a trial-and-error approach. A critical review of simulation strategies was published by Bertini et al. [19], comparing mesoand macro-scale models. In the past, meso-scale models could provide the required detail but were highly complex and computationally intensive, whereas macro-scale simulations could cover large structures but required excessive abstraction which limited their accuracy. An up-to-date review of literature leads to the conclusion that meso-scale models are mature in their ability to accurately predict residual stress, whereas macro-scale models are still emerging.

\subsection{Modelling of wire-fed laser DED}

Pinkerton [20] subdivided the approaches to physical modelling of DED into the models of power stream processes; models of melt pool processes; and models of microstructure, stress and final geometry. These divisions highlight the issues related to wire-fed material deposition, as the majority of the developments in physical modelling have historically been focused on powder stream-based process. This paradigm has since begun to change. A comprehensive simulation of wirefed laser cladding was carried out by $\mathrm{Li}$ et al. [21], which predicted the size and shape of the melt pool and the extent of its penetration into the substrate, averaging errors of $20 \%$. So far, this has only been used for single tracks, with further development required for multi-track deposition. Additionally, gravity and pressure effects for wire-fed laser DED were investigated by $\mathrm{Gu}$ and $\mathrm{Li}$ [22] on single track deposits. The gravity vector was found to have significant impact on melt pool formation. Ambient pressure reduced the vaporisation temperature of the liquid metal and increased the amount of vapour produced. Alterations to laser power and scanning speed were proposed to counter these effects.

Multi-track depositions of wire-fed Ti-6Al-4V, using a tophat laser beam, were simulated by Chua et al. [23]. They investigated the effects of different deposition strategies - directions, patterns and interpass times - on temperature distributions, vertical displacement and residual stress.

The literature review of DED modelling has identified two areas of opportunity for the development of wire-based deposition, the control of heat input, and the unique heat transfer situation in terms of geometry and heat flux before wire melting. This paper investigates these phenomena through the following research question: To what extent does the control of heat input geometry (in this case, the laser beam thermal profile) and substrate heating affect the temperature distribution in the solid phase of wire-fed DED?

This question was investigated through heat flow simulations at different beam geometries. Holographic Optical Elements (HOE's) were then used to create physical laser beams that match the simulated heat fluxes. Experimental results are then compared to simulations in order to evaluate the effects of substrate heating.

\section{Simulation setup}

Because the materials were opaque at the $1070 \mathrm{~nm}$ laser wavelength, the laser was treated as a surface heat source. Numerical simulations were therefore set up with the "Heat Transfer in Solids" module in COMSOL Multiphysics (Version 5.0, COMSOL, Stockholm, Sweden). The purpose of this model was to evaluate pre-melt substrate heating only. Assumptions were: 
- The laser beam produces a surface heat flux of the desired shape-see Section 2.1.

- Laser beam energy is absorbed within a negligible distance of the material surface - there is no volumetric heating.

- The fraction of laser light that is reflected is permanently removed and does not reflect back.

- Melting, fluid flow and wire feeding are assumed not to occur, for the purposes of simulation.

An AISI 316 stainless steel wire, $1 \mathrm{~mm}$ diameter $\times 35 \mathrm{~mm}$ long, was placed on a $35 \times 15 \mathrm{~mm}$ mild steel substrate, $0.8 \mathrm{~mm}$ thick. In order to avoid a tangential, single-node connection, the wire and substrate were overlapped slightly (Fig. 1), with the wire depressed $0.03 \mathrm{~mm}$ into the substrate. This avoided computational errors, while keeping the connection as close to tangential as possible.

A free tetrahedral mesh was defined, with physicscontrolled meshing used to generate the element sizes, in a similar way to Yadav et al. [24]. This gave substrate maximum and minimum element sizes of $2.8 \mathrm{~mm}$ and $350 \mu \mathrm{m}$, respectively, and wire element size limits of $400 \mu \mathrm{m}$ and 3 $\mu \mathrm{m}$. This yielded a biased mesh with approximately 14900 elements, shown in Fig. 2, which focussed mesh refinement around the region of interest (the wire and adjacent substrate).
This maximised precision, while minimising computational load - typically around $30 \mathrm{~min}-2 \mathrm{~h}$, depending on workstation usage.

Boundary conditions "Convective Cooling" and "Surface to Ambient Radiation" were applied. Model properties were all defined as given in the Appendix. Material reflectivity/ absorptivity was defined manually, according to the methodology briefly described in Section 2.1. A full analysis of wire reflectivity was previously published by Goffin et al. (2015), but is summarised here for convenience.

\subsection{Governing equations}

The time-dependent energy conversion equation is as follows [25]:

$\rho C_{p} \frac{\partial T}{\partial t}=\nabla(k \nabla T)+Q$

where $\rho$ is material density, $C_{p}$ is specific heat capacity, $T$ is temperature, $t$ is time, $k$ is thermal conductivity and $Q$ is the volume heat source due to laser power.

The incident heat source, $Q$, is a function of the Irradiance, Irradiance Distribution (either Gaussian or uniform) and material absorptivity. In the case of laser heating

Fig. 1 Wire and substrate overlap

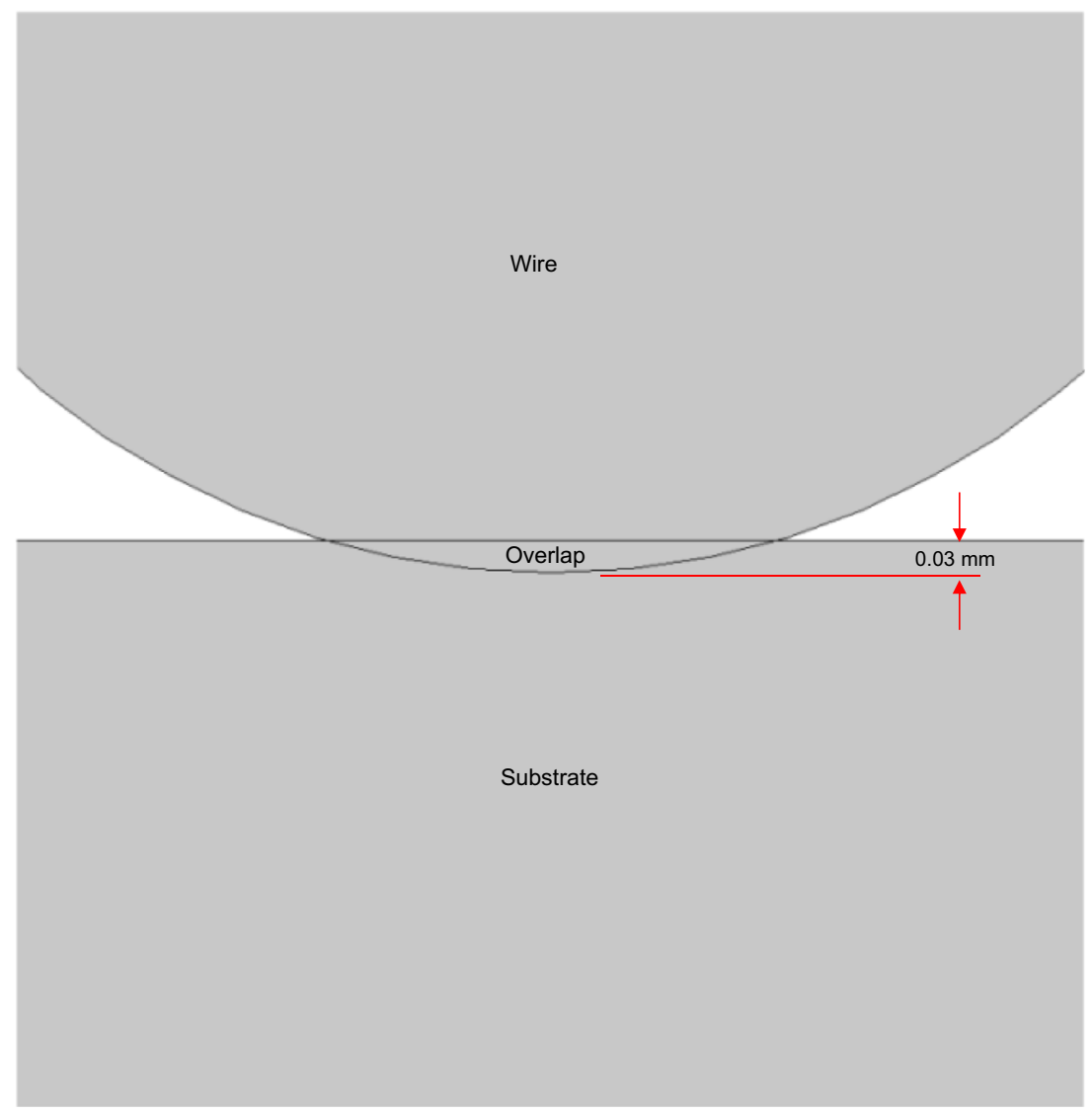


Fig. 2 Wire simulation mesh, with wire (blue) and substrate (red). Dimensions in $\mathrm{mm}$

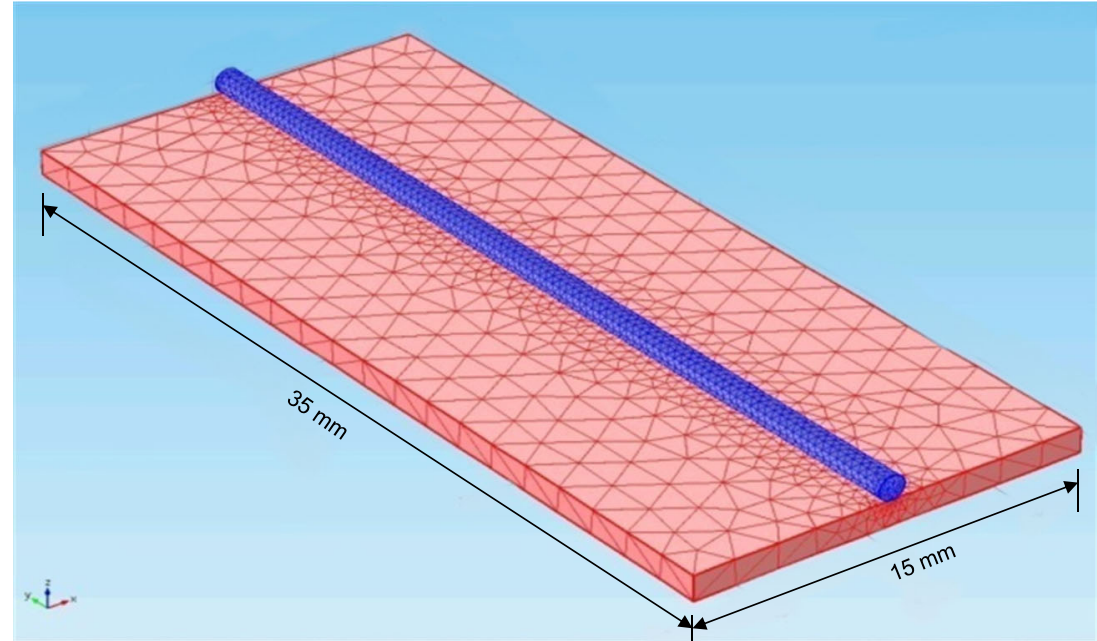

with a Gaussian beam in COMSOL, $Q$ is represented via a "Gaussian Pulse" function (gp1), created with a standard deviation, $\sigma$, of $1 / 2$. This function defined a bell-curve according to the expression:

$y(x)=\frac{1}{\sigma \sqrt{2 \pi}} e^{\frac{-\left(x-x_{0}\right)^{2}}{2 \sigma^{2}}}$

where in this application $y(x)$ is the laser beam power, $\sigma$ is the standard deviation and $x$ is the position within the beam. When $\sigma=1 / 2$, this reduces to:

$y(x)=\frac{1}{2 \sqrt{2 \pi}} e^{-2\left(x-x_{0}\right)^{2}}$

This creates a Gaussian laser beam plot bounded by $x$. When used in the Gaussian heat flux function, $x$ was equal to the beam radius, giving an equivalent $1 / \mathrm{e}^{2}$ beam diameter equal to the "r_beam" parameter from Table 3 in the Appendix.

Absorptivity was applied by multiplying the beam plots by the material absorption co-efficient. In the case of the flat mild steel substrate this was a simple multiplication, but in the case of the curved wire surface, the absorptivity changed with incidence angle across the width of the wire.

Reflectivity is a function of the complex refractive index of the material, and the angle of the incident light. Complex refractive index takes the form [27]:

$m=n-j k$

where $m$ is the complex index of refraction, $n$ is the refractive index and $k$ is the absorption index. For stainless steel under a $10.6 \mu \mathrm{m}$ laser, $n=20.4$ and $k=21.5$ [28].

Fresnel relations connect the refractive index and incidence angle to reflectivity, and for metals (due to their relatively high refractive index) can be simplified to:
Parallel-polarised light :

$$
\rho_{\|}=\frac{(n \cos \theta-1)^{2}+(k \cos \theta)^{2}}{(n \cos \theta+1)^{2}+(k \cos \theta)^{2}}
$$

Perpendicular-polarised light :

$$
\rho_{\perp}=\frac{(n-\cos \theta)^{2}+k^{2}}{(n+\cos \theta)^{2}+k^{2}}
$$

Circular polarised light can then be defined as an average of the two:

$\rho=\frac{\rho_{\|}+\rho_{\perp}}{2}$

Reflectivity can then be plotted with respect to incidence angle, as shown in Fig. 3. These incidence angles can be related to transverse position on the wire surface and used to generate a wire-specific reflectivity profile.

\subsection{Modelling laser beam heat fluxes}

The COMSOL Heat Transfer Module was used to generate heat fluxes to simulate the laser beam, similarly to Ya et al. [29]. It was profiled mathematically and then split into two sections, one heat flux for the wire and a separate one for the substrate, which accounted for their differing reflectivities and surface geometries. These were then simultaneously combined into a single laser beam heat flux that accurately reflected the differences between the wire and substrate. The two heat fluxes were as follows:

- Direct Wire Heating (DWH): Incorporating the reflectivity profile described previously by Goffin et al. [26] to accurately model the curved surface of the wire, with the laser illuminating the wire only. 
Fig. 3 Reflectivity vs. incidence angle for stainless steel illuminated by a $10.6 \mu \mathrm{m} \mathrm{CO}$ laser [26] (reproduced with permission)

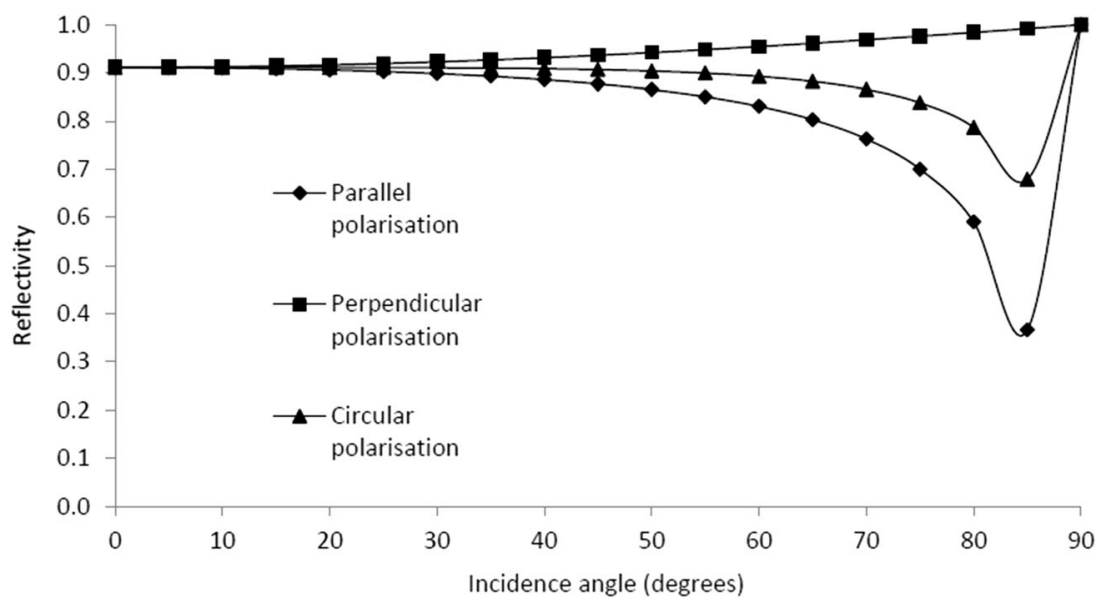

- Direct Substrate Heating (DSH): Incorporating the illumination of the substrate. No reflectivity profile was necessary since it was a flat surface.

Three different laser beam profiles were studied; selected for their effects on the wire and substrate:

- $1.25 \mathrm{~mm}$ diameter Gaussian beam

- $1.25 \mathrm{~mm}$ width square pedestal beam

- $3.5 \mathrm{~mm}$ diameter Gaussian beam

These three beam types gave two types of intercomparison: The $1.25 \mathrm{~mm}$ Gaussian and pedestal beams had equal widths with different energy distributions, while the two Gaussian beams had equal energy distributions with different widths.

These heat fluxes were coded in COMSOL, with boundary conditions, using the codes given in Table 1. Parameters and variables are given in the Appendix.

\subsection{DWH flux modelling}

The reflectivity profile had been previously calculated by Goffin et al. [26] (shown in Fig. 3) and was here inverted and applied as an absorptivity profile in two dimensions, bounded by the wire diameter in one direction and beam length in the other. This was applied to the Gaussian and pedestal heat fluxes, giving the plots (Fig. 4).

These were then added to the top surface of the wire, bluehighlighted in Fig. 5a. The resultant temperature plot is given in Fig. 5b.

\subsection{DSH flux modelling}

Division of the substrate was required, as shown in Fig. 6, to account for shadowed areas. No complex reflectivity profile was required since it was a simple flat surface, with reflectivity just a single co-efficient. Figure 7 shows the resultant temperature plot, which shows the effect of the part of the laser beam that hits the substrate. When this heat flux was applied contemporaneously with the DWH heat flux, a complete picture of the entire heat effect of the laser beam was created, simultaneously accounting for differences in geometry and reflectivity.

\section{Experimental procedure}

A summary of the experimental procedure is presented here, since it was identical to that used by Goffin et al. [26]. $\mathrm{A} \mathrm{CO}_{2}$ laser (Coherent Everlase S48) with $1.2 \mathrm{~kW}$ maximum power was used for experiments. An AISI 316 stainless steel wire, diameter $1 \mathrm{~mm}$, was pre-placed onto a mild steel substrate that was $0.8 \mathrm{~mm}$ thick, matching the simulation geometry. A 4-s delay was applied for melt pool initiation, followed by a 1.6 $\mathrm{mm} / \mathrm{s}$ traverse velocity. Samples were sectioned and etched using Kalling's \#2 reagent, then imaged using bright-field optical microscopy to reveal microstructure.

The simulated beam shapes were created using Holographic Optical Elements (HOE's), originally developed by Tyrer and Noden [30], in the same way as Goffin et al. [26].

Table 1 COMSOL codes for laser beam heat fluxes

\begin{tabular}{|c|c|}
\hline Description (name) & Function \\
\hline Applied Gaussian heat flux (Q_app) & $(\mathrm{P} \text { laser/r_beam^2})^{*} \operatorname{gp} 1\left((\mathrm{x}-\mathrm{x} 0) / \mathrm{r} \_ \text {beam }\right)^{*} \mathrm{gp} 1((\mathrm{y}-\mathrm{y} 0) / \mathrm{r}$ _beam $)$ \\
\hline Applied pedestal heat flux (Q_app_ped) & P_laser $\left(4 *\right.$ r_beam $\left.{ }^{\wedge} 2\right) * i f(a b s(x-x 0)<=r$ beam $, 1,0) * i f(a b s(y-y 0)<=r$ beam $, 1,0)$ \\
\hline
\end{tabular}


Fig. 4 Three-dimensional plots (all $1 \mathrm{~mm}$ width) showing (a) wire absorptivity plot, (b) resultant Gaussian DWH flux and (c) resultant pedestal DWH flux (a)

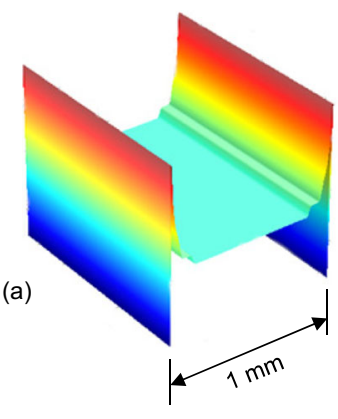

(b)

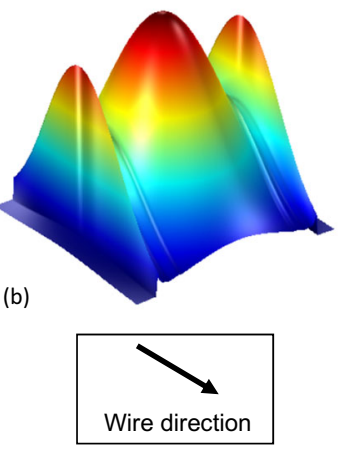

(c)

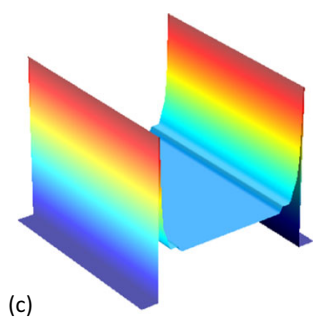

Fig. 5 (a) Areas of heat flux application (blue). (b) Resultant temperature distribution (Gaussian beam)
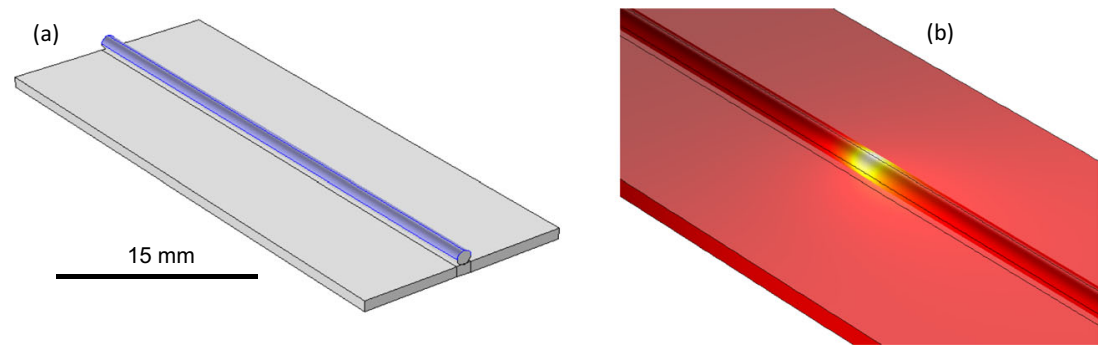

Comparisons between the two are given in Fig. 8. Simulation analyses were carried out at 3,2 and 1 dimensions.

\subsection{D evaluation}

$3 \mathrm{D}$ evaluations studied the temperature distributions and $3 \mathrm{D}$ heat fluxes. Isothermal contours and heat flux vectors are shown in Fig. 9. Because the maximum temperatures were so different, each beam type is shown with an individual temperature scale. If all were plotted using the same scale, at least one beam type result would have no visible temperature distribution and would be a uniform colour.

The isothermal contour and heat flux patterns are highly similar with all beam types, showing that heat flow is highly influenced by geometry. The bulk of heat flow is ahead of the beam traverse, with heat conducting away in an elliptical pattern.

There are, however, specific differences between the types. With the two $1.25 \mathrm{~mm}$ beams, heat is concentrated in the wire
( $85.4 \%$ of beam irradiance), with the largest flux central down to the substrate. With the larger Gaussian beam, $64 \%$ of the spot illuminates the substrate, reducing the wire-substrate heat flux and increasing heat flux in the substrate itself. This reduced wire heat flux is also caused by the larger beam area reducing the power density.

\subsection{D evaluation}

Figure 10 shows the $2 \mathrm{D}$ analysis plane in the centre of the wire and substrate. Plots were then set at time intervals where the analysis plane bisected the heat fluxes.

Figure 11 shows temperature distribution and isothermal contours at 20 levels for all three beam types. Again, individual temperature scales have been used, for the same reason as in Fig. 9.

The thermal gradient is steepest in the $1.25 \mathrm{~mm}$ Gaussian plot, with thirteen contours present in the wire. The $1.25 \mathrm{~mm}$

Fig. 6 Schematic showing substrate division for wire shadowing

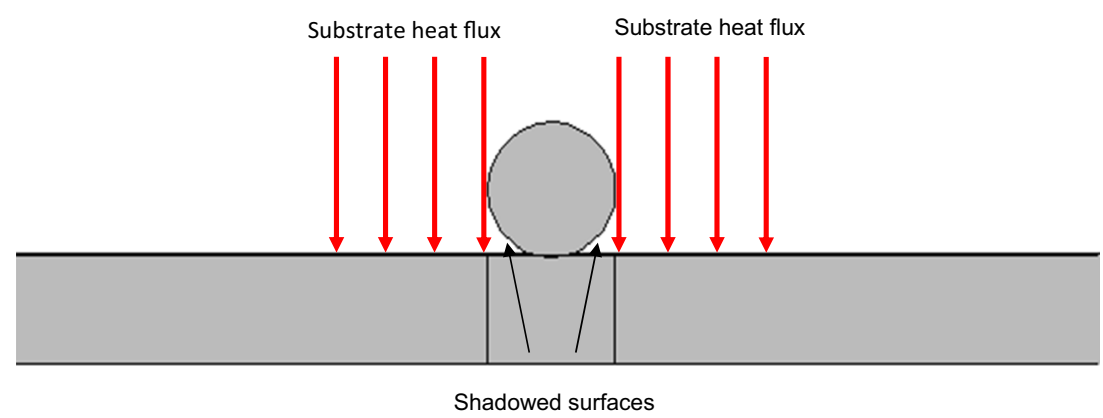




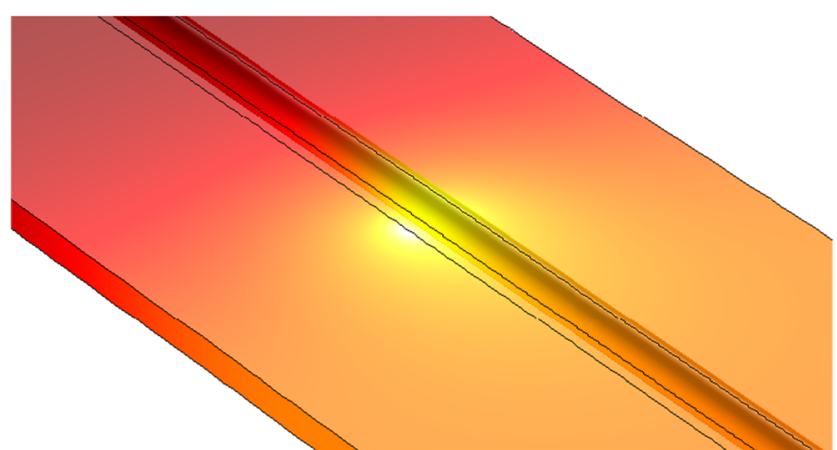

Fig. 7 Example Gaussian substrate-only temperature distribution

pedestal simulation has eleven present and the large Gaussian seven, showing that their thermal gradients are shallower.

Wire thermal gradient is governed by the level of direct wire heating. In the smaller Gaussian beam, its diameter and thermal profile mean that almost all the beam energy is incident on the wire and concentrated in the centre. The pedestal beam's uniformity causes it to input additional heat to the edge of the wire and into the substrate, which reduces the thermal gradient in the wire.

The smallest difference between the substrate and the wire temperatures occurs with the large Gaussian beam. Its size means that it illuminates the substrate with a much higher percentage of its total energy, despite its non-uniformity. This heats the substrate more effectively compared to the other two beams, which also causes the reduced thermal gradient compared to the other two beam types.

Absorptivity is much higher at the edges of the wire than at the centre. This affects the shape of the isothermal contours, shown in Fig. 11. The $1.25 \mathrm{~mm}$ Gaussian simulation has almost flat contours because the absorption and heat flux profiles are opposed, reflectivity being highest where heat flux is strongest.
For the other two simulations $(1.25 \mathrm{~mm}$ pedestal, $3.5 \mathrm{~mm}$ Gaussian), the curvature is increased due to the higher heat flux uniformity across the wire width. This is more true of the pedestal beam (fully uniform) than of the $3.5 \mathrm{~mm}$ Gaussian beam (heat input reduces at the edges, due to its Gaussian shape), which results in greater edge curvature of the isothermal contours in that simulation.

\subsection{D evaluation}

Temperature measurements were plotted both longitudinally and vertically at specific areas of interest:

- Horizontally, along the full length of the wire at the top surface.

- Vertically, through the centre of the wire and substrate.

Figure 12 shows longitudinal temperature plots. All three simulations behave similarly; the wire leading the beam is at starting temperature (room temperature), which rises at $x=22.5 \mathrm{~mm}$ with the beam's approach. The temperature maximises at approximately the beam centre $(x=$ $17.5 \mathrm{~mm}$ ).

Trailing the beam, temperature reduces, but stabilises at a higher temperature than the starting temperature. This is because substrate heating has reduced the ability of heat to conduct away from the wire, leaving less-efficient convection into the surrounding air as the primary means of heat loss.

The maximum wire temperature reached changes according to the beam type, with the two $1.25 \mathrm{~mm}$ beams reaching approximately $3000^{\circ} \mathrm{C}$ and the $3.5 \mathrm{~mm}$ beam much lower. Its primary driver is beam size, since the larger beam applies less energy to the wire and more to the substrate, in addition to
Fig. 8 Perspex laser burn prints (a) Gaussian profile and (b) pedestal profile, compared to simulated plots

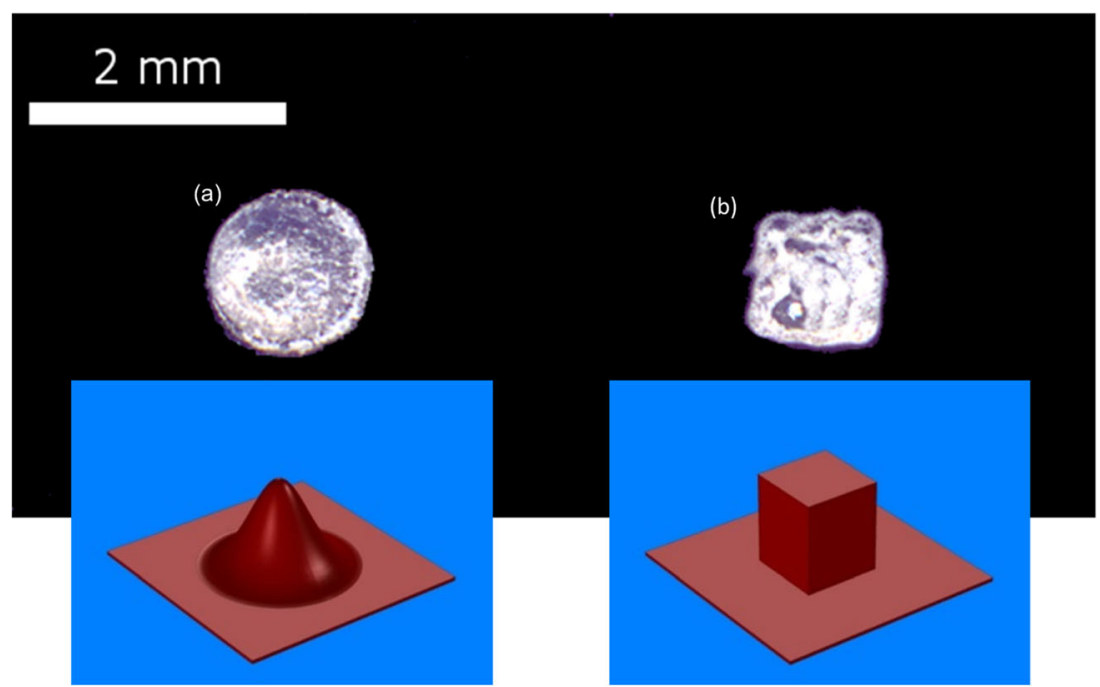


Fig. $93 \mathrm{D}$ isothermal contours and heat flux vectors for (a) $1.25 \mathrm{~mm}$ Gaussian, (b) $1.25 \mathrm{~mm}$ pedestal and (c) $3.5 \mathrm{~mm}$ Gaussian beams. Arrow size and direction show heat flux magnitude and vector
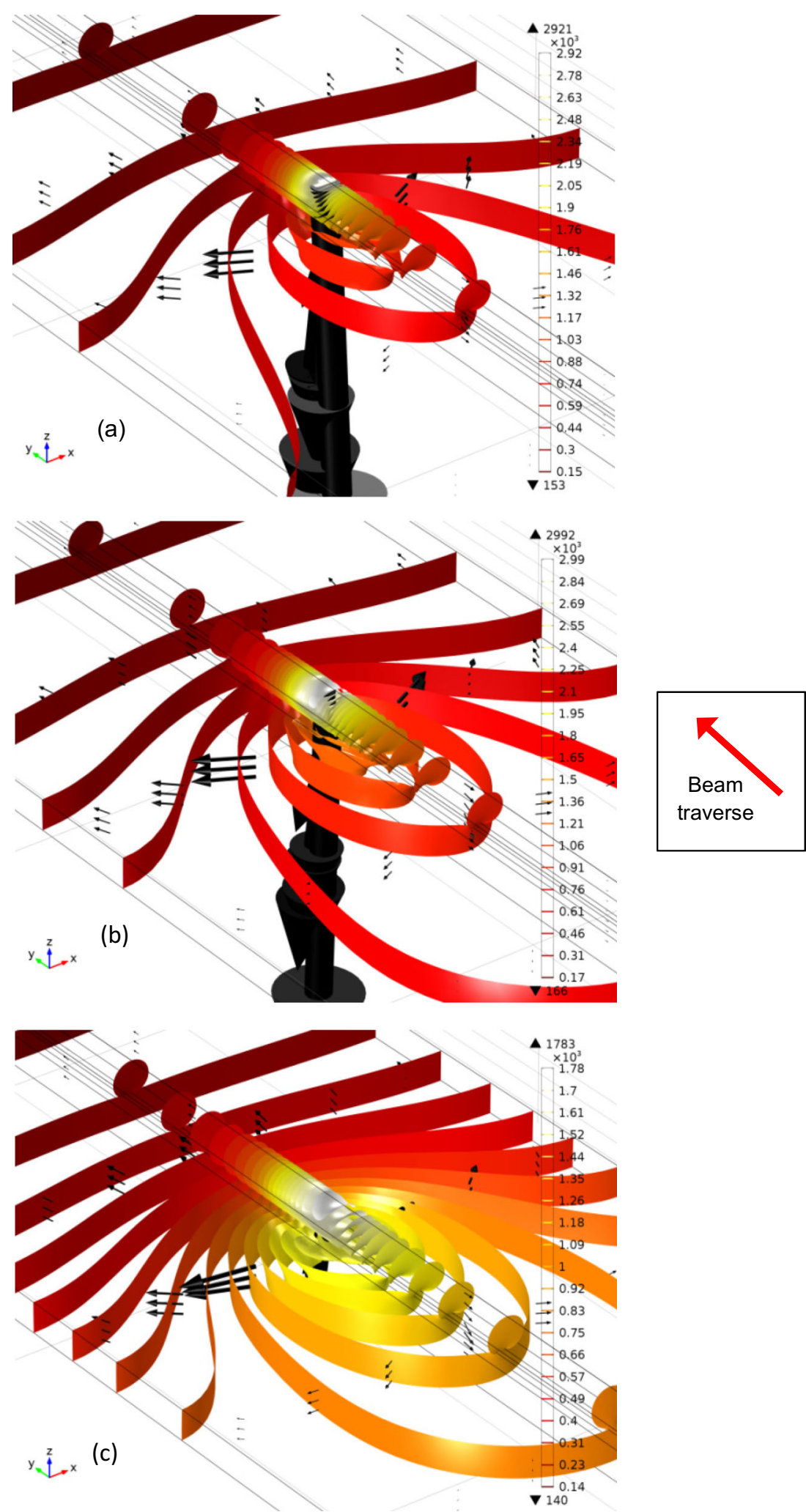

having a lower power density. While the two $1.25 \mathrm{~mm}$ beams heat up in a similar fashion, their cooling curves show significant differences. There are two causes involved:
- Length uniformity: $1.25 \mathrm{~mm}$ Gaussian beam is nonuniform along its length, whereas the pedestal beam is uniform. Heating with the pedestal beam therefore takes 


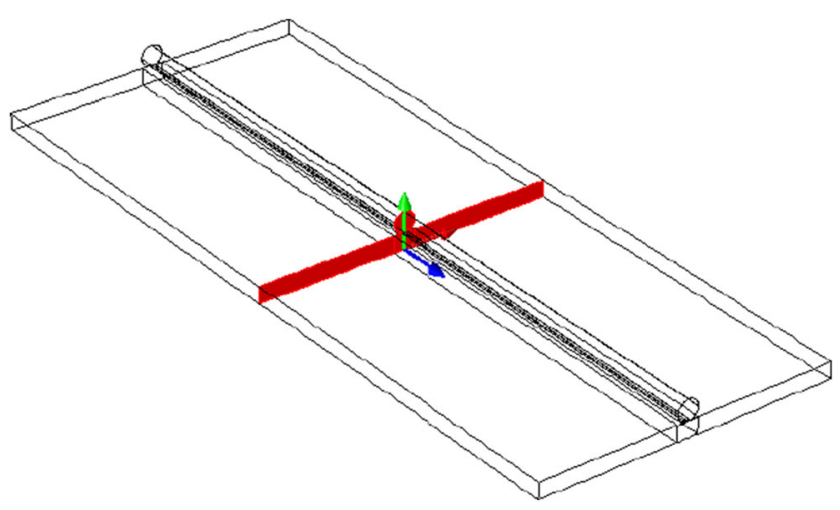

Fig. 10 2D cut plane used for sectional temperature profiles

place for a longer time, leading to a higher trailing temperature.

- Substrate heating capability: In Fig. 10 , the $1.25 \mathrm{~mm}$ pedestal beam is more effective at substrate heating than the $1.25 \mathrm{~mm}$ Gaussian beam. More substrate heating reduces the wire-substrate heat flux, reducing the cooling effect of the substrate and causing the temperature to stabilise at a higher level.

The $3.5 \mathrm{~mm}$ beam's longer length gives it a shallower cooling gradient than the smaller beams for a similar reason to the $1.25 \mathrm{~mm}$ pedestal - the incident heat flux is maintained for longer. Similarly to the $1.25 \mathrm{~mm}$ pedestal beam, the temperature gradient in the wire is reduced by greater substrate heating, but to a greater extent due to the larger beam. The wire temperature therefore stabilises slightly above the $1.25 \mathrm{~mm}$ pedestal beam.

Figure 13 shows vertical temperature plots through both wire and substrate.

The steepest temperature gradients are present in the wire for all three beam types. The wire-substrate interface limits conduction from wire to substrate, which accounts for this difference. The higher uniformity of substrate temperature is because the larger substrate volume allows heat to dissipate in all directions. This reduces the thermal gradient in the specific vector currently under consideration.

Direct substrate heating levels also contribute to substrate temperature differences. The substrate temperature is reduced with the smaller Gaussian beam compared to the other two types, due to its reduced substrate heating compared to the other two. The pedestal and the larger Gaussian beams have the substrate at similar temperatures, similar levels of energy input into the substrate through the wire-substrate interface. The larger $3.5 \mathrm{~mm}$ Gaussian beam has greater energy striking the substrate overall, but the large size of the beam means that much of this is a considerable distance from the centreline, compared to the smaller pedestal beam where it is all close by. The $1.25 \mathrm{~mm}$ Gaussian beam model presents the greatest overall temperature difference, with a temperature reduction of approx. $1750{ }^{\circ} \mathrm{C}$ between the wire top and the wire-substrate interface. This compares to a $1450{ }^{\circ} \mathrm{C}$ difference with the pedestal beam and a $400{ }^{\circ} \mathrm{C}$ difference with the larger Gaussian beam.

The highest rate of change in the $1.25 \mathrm{~mm}$ Gaussian beam was in the top $0.3 \mathrm{~mm}$ of the wire. Below this, the $1.25 \mathrm{~mm}$ Gaussian beam cools at the same rate as the pedestal beam, but at a lower temperature. The $1.25 \mathrm{~mm}$ Gaussian beam has its irradiance maximised at the wire centre, which is limited in the rate at which it can conduct into the substrate. This is why its temperature plot gets steeper towards the upper third of the wire.

Additional heat is applied at the edges of the wire in both the pedestal and $3.5 \mathrm{~mm}$ Gaussian beams compared to the smaller Gaussian beam. More conduction vectors are therefore available for heat to leave the wire (shown by the pattern of isothermal contours in Fig. 10) and so no temperature concentration exists with those beams. The wire cooling lines are therefore linear for both beam types.

\section{Experimental results}

Experimental results used to evaluate the simulations were originally presented by Goffin et al. (2015). For convenience, a selection of these results is replicated here for discussion and comparison with simulation results. Figure 14 shows the $1.25 \mathrm{~mm}$ Gaussian results, Fig. 15 shows results from the $1.25 \mathrm{~mm}$ pedestal beam and Fig. 16 shows the $3.5 \mathrm{~mm}$ Gaussian clad tracks. In order to aid in analysis, all results are reported in terms of power density $\left(\mathrm{W} / \mathrm{mm}^{2}\right)$.

In Fig. 14, the wire has retained its shape as the power density increased. As marked with red ellipses, melting has fused the wire to the substrate without much evidence of the formation of a melt pool. The microstructures show that there has been minimal mixing of the wire and substrate material. This indicates that, like Fig. 8, the primary heat flux has been from the substrate to the wire.

Figure 15 shows the effects when a pedestal beam more effectively heats the substrate directly. In this case, a melt pool forms more easily at a reduced power density compared to the Gaussian beam in Fig. 13. At the lowest power density, there has been sufficient heat into the wire to produce the delta ferrite structure typically seen in stainless steel laser welds [31]. The wire has clearly been melted, but there is insufficient heating for it to form a true melt pool and wet the substrate. At $190 \mathrm{~W} / \mathrm{mm}^{2}$ there has been some mixing of the wire and substrate although the stainless steel exhibits a similar structure to that at 170 $\mathrm{W} / \mathrm{mm}^{2}$. At $210 \mathrm{~W} / \mathrm{mm}^{2}$ there has been considerable 
Fig. 11 Temperature and isothermal contour distributions $\left({ }^{\circ} \mathrm{C}\right)$ for (a) $1.25 \mathrm{~mm}$ Gaussian beam, (b) $1.25 \mathrm{~mm}$ pedestal beam and (c) $3.5 \mathrm{~mm}$ Gaussian beam

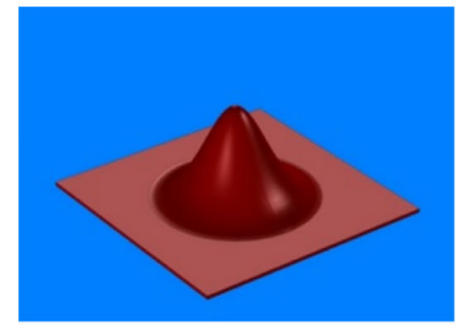

$1.25 \mathrm{~mm}$ gaussian beam

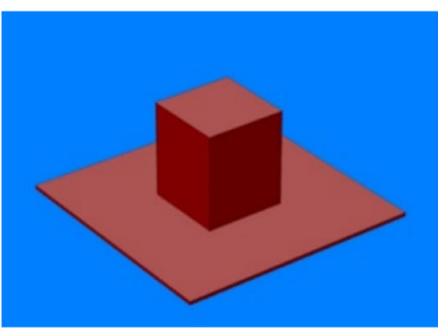

$1.25 \mathrm{~mm}$ pedestal beam

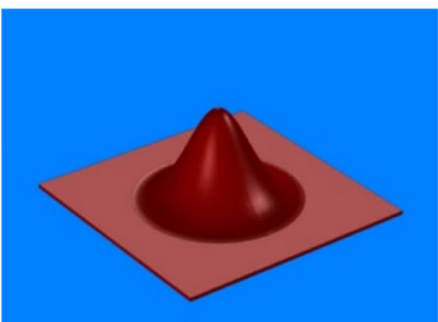

$3.5 \mathrm{~mm}$ gaussian beam
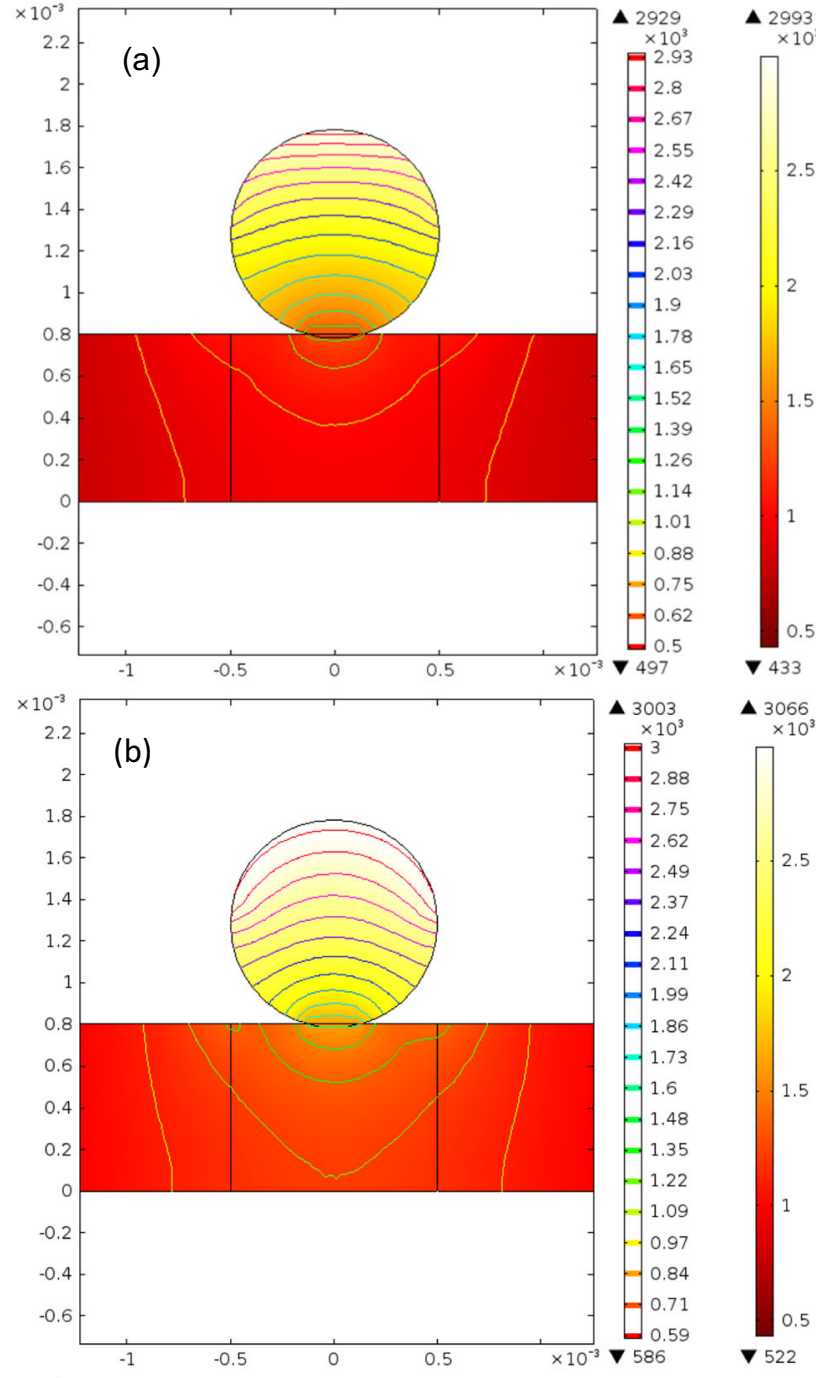

A 3066
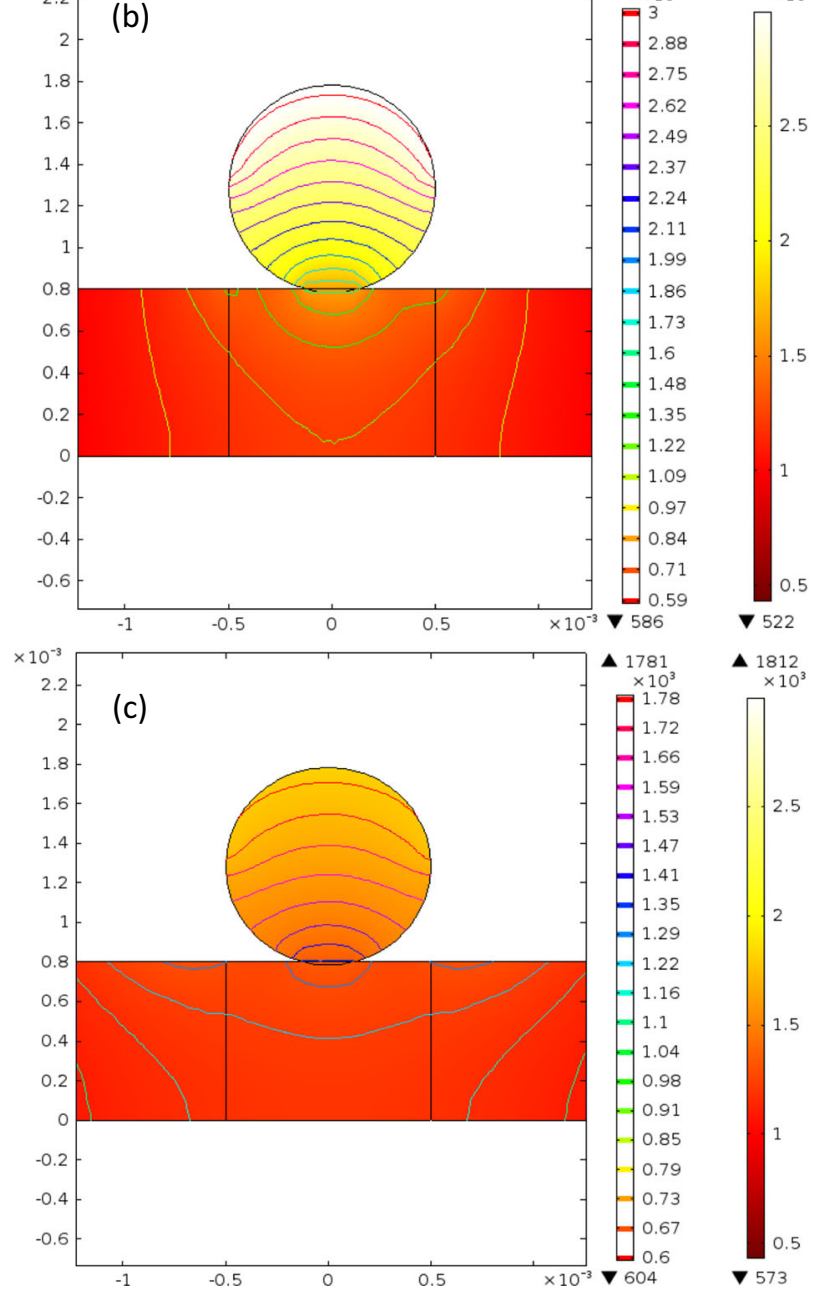

mixing between the wire and substrate as the structure within the deposit exhibits a martensite/bainite structure. There is almost complete penetration through to the other side of the steel substrate.
The larger Gaussian beam results are shown in Fig. 16. The lowest energy density shows no wetting of the substrate by the wire, though the wire has again clearly been melted. In a similar way to Fig. 15, a melt pool is 
Fig. 12 Temperature plots along the wire

Fig. 13 Vertical temperature plots for all three beam types
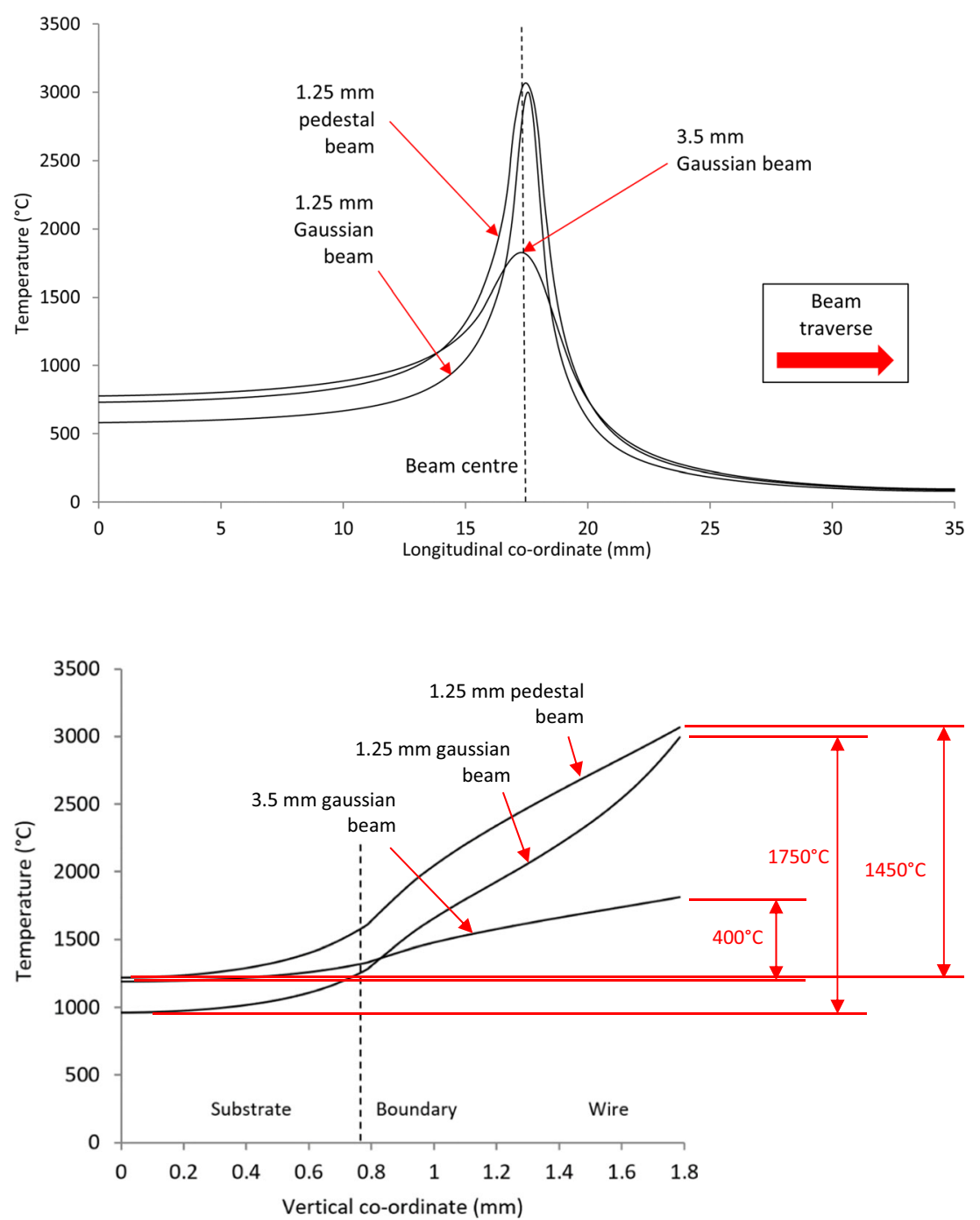

easily formed but the range of suitable power densities is much narrower. There is considerable mixing in the $42 \mathrm{~W} / \mathrm{mm}^{2}$ sample, and at $47 \mathrm{~W} / \mathrm{mm}^{2}$ there is over penetration and mixing the alloys with the boundary between the stainless steel and mild steel difficult to distinguish. The structure is fully martensitic, indicating that there has been complete mixing as well as a high cooling rate of the heated area. The results indicate that

Fig. $141.25 \mathrm{~mm}$ Gaussian beam clad tracks

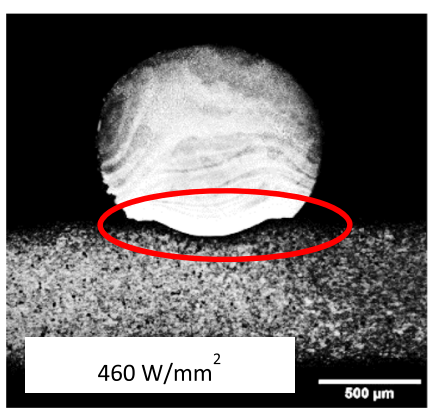

direct substrate heating is, therefore, effective at promoting melt-pool formation.

\section{Discussion}

The simulations predicted fully melted wires with the maximum temperature at the wire top surface. This contradicted the
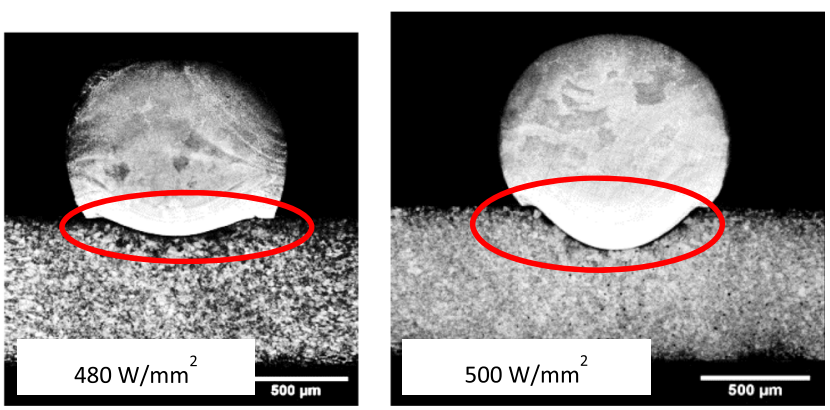
Fig. $151.25 \mathrm{~mm}$ pedestal beam clad tracks
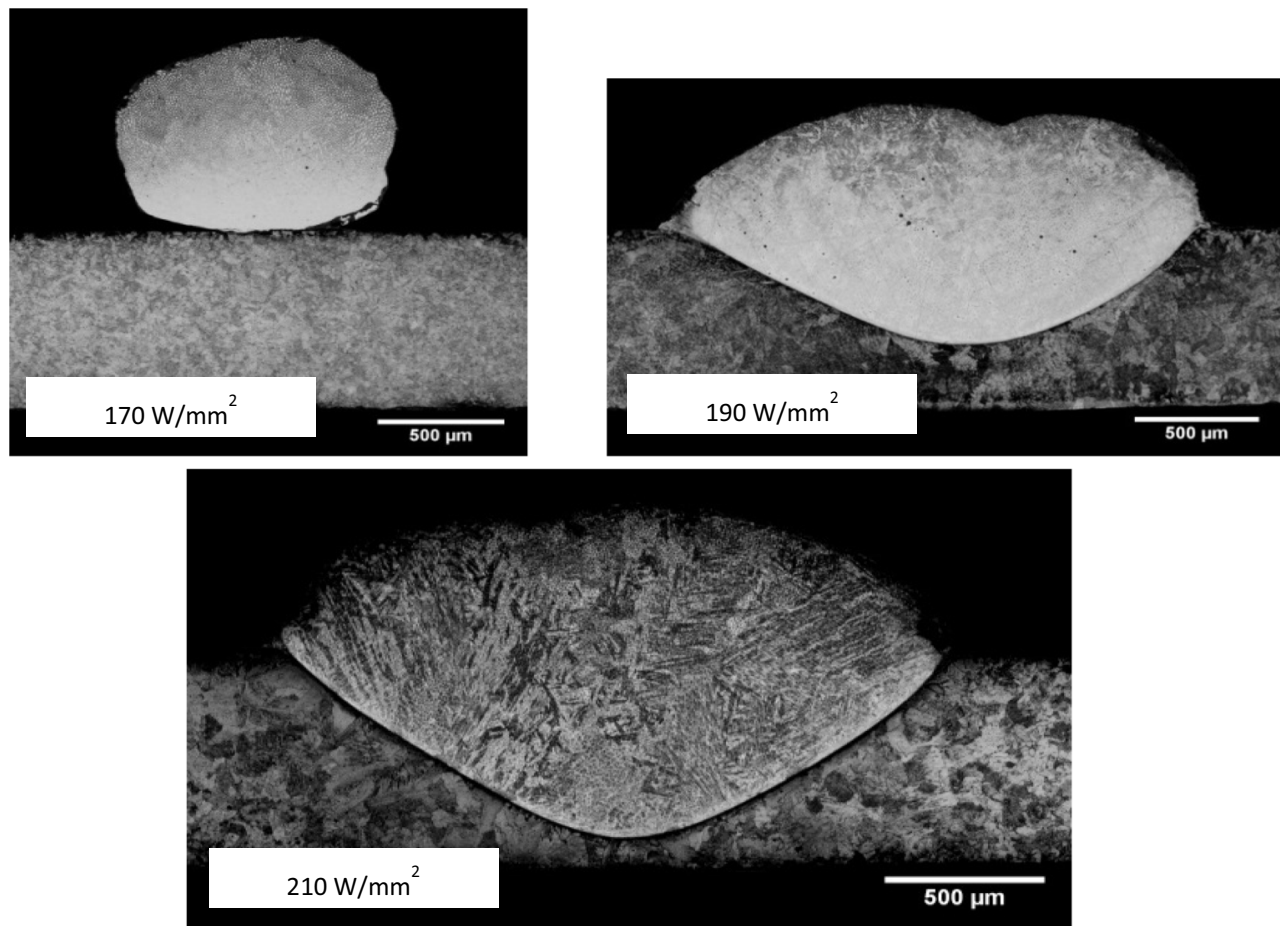

experimental results, which clearly showed melt initiation at the wire-substrate boundary. This is most obvious in Fig. 17.

Simulations predict greater substrate heating in the $3.5 \mathrm{~mm}$ vs. the $1.25 \mathrm{~mm}$ Gaussian beam, the $1.25 \mathrm{~mm}$ pedestal vs. $1.25 \mathrm{~mm}$ Gaussian and $3.5 \mathrm{~mm}$ Gaussian vs. $1.25 \mathrm{~mm}$ pedestal. Therefore, there was a clear link between the heating of the substrate and applied beam shape, which has not so far been covered in the literature. If the beam can apply heat to the substrate directly, instead of relying on conduction through the wire, the substrate can reach a high temperature with a lower level of laser beam power.

This ties directly into the experimental results, which show that wetting is more effective at lower power densities with the $3.5 \mathrm{~mm}$ Gaussian and pedestal beams, the ones which directly

Fig. $16 \quad 3.5 \mathrm{~mm}$ Gaussian beam clad tracks
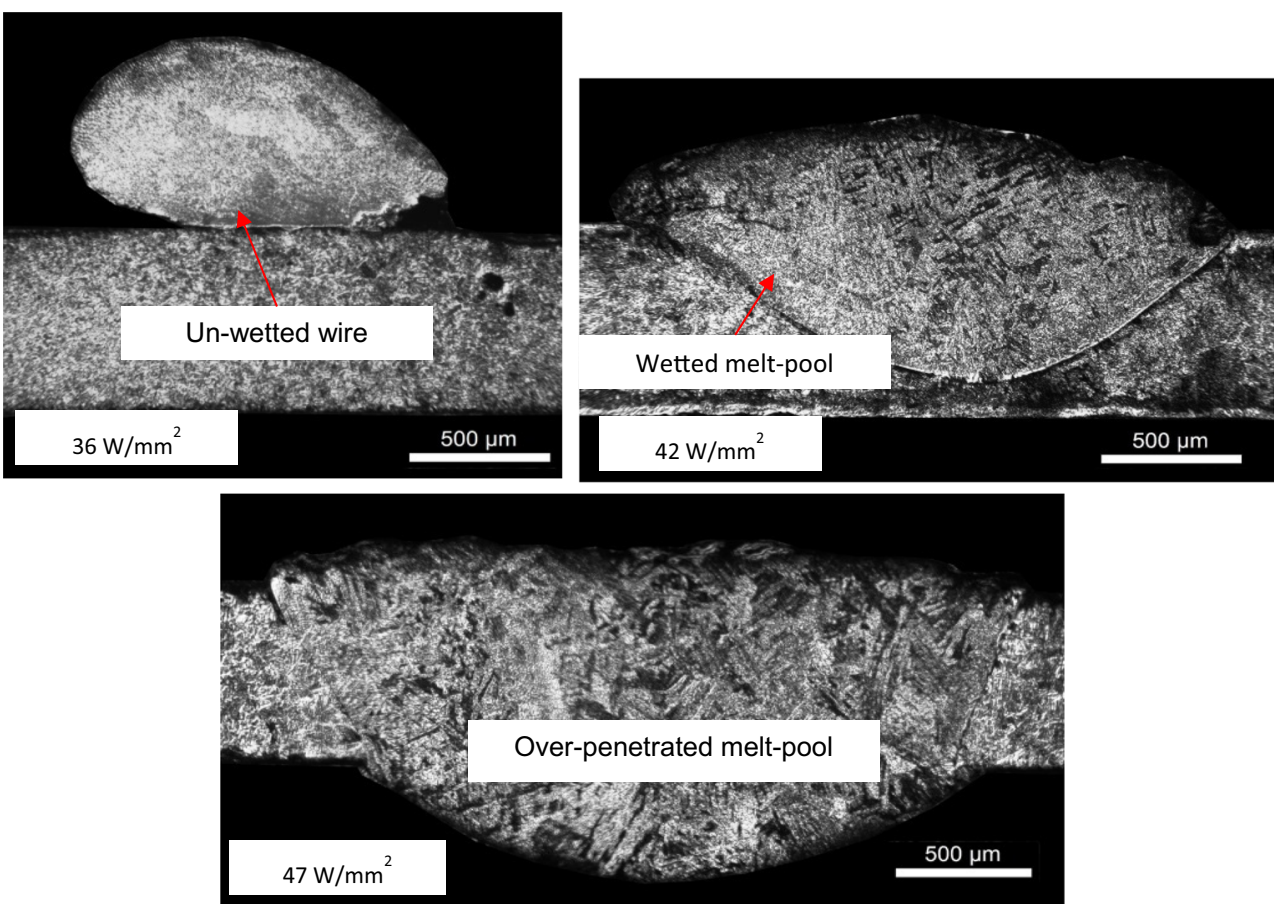

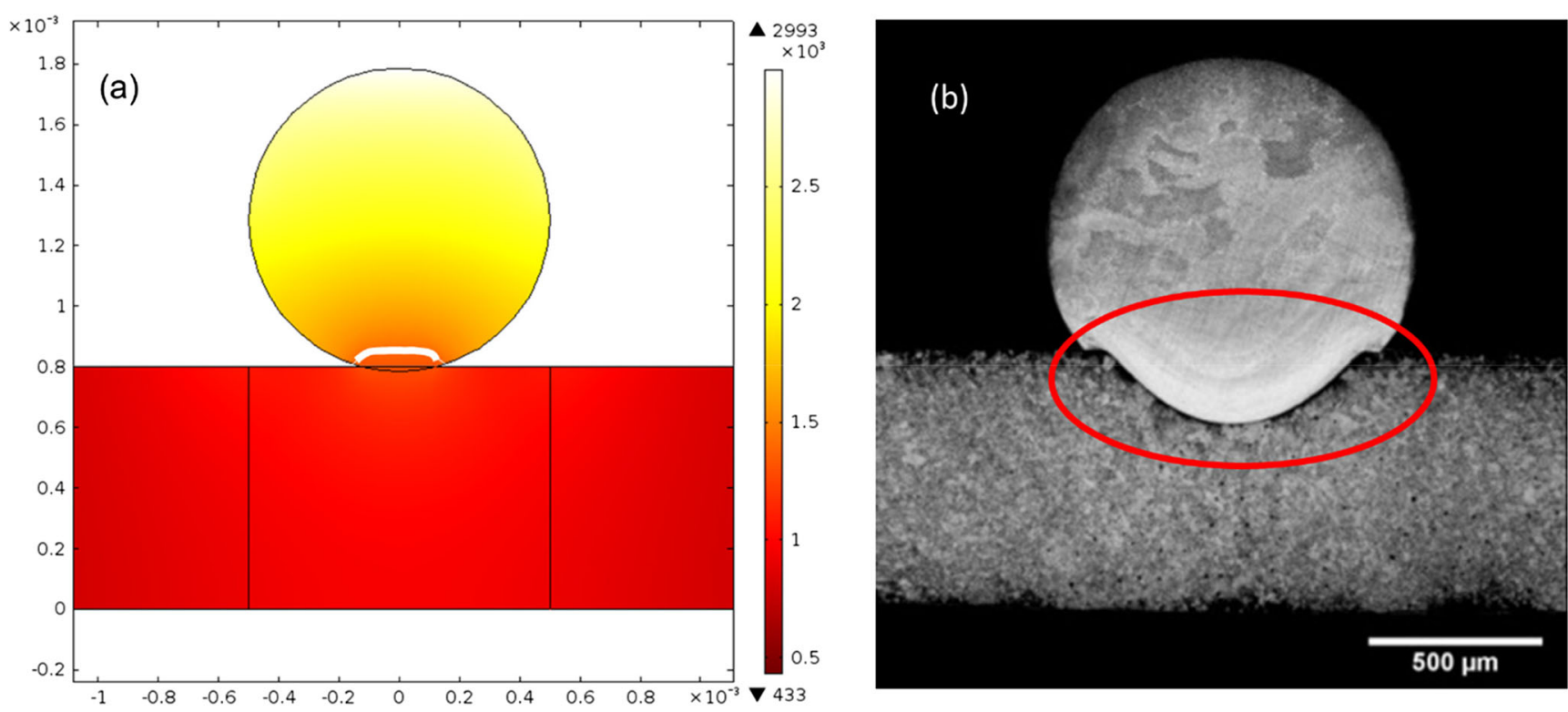

Fig. 17 (a) $1.25 \mathrm{~mm}$ Gaussian beam melting prediction (solid-liquid boundary highlighted in white) $\left({ }^{\circ} \mathrm{C}\right)$. (b) Experimental melting results showing actual site of melt pool initiation (circled in red)

heat the substrate, than with the $1.25 \mathrm{~mm}$ Gaussian beam. When the two beams are the same size, the greater amount of heat applied at the edge of the uniform pedestal gives more effective substrate heating than with the non-uniform Gaussian beam since heat is applied to the substrate directly, whereas the $1.25 \mathrm{~mm}$ Gaussian beam is reliant on conduction into the substrate through the wire. This suggests that significant substrate heating greatly assists melt pool wetting.

These lower required power densities (predicted in simulation and experimentally verified) translated directly into lower overall beam power when the different beam sizes were taken into account, as shown in Table 2. Changing the Gaussian beam to a square pedestal beam, while keeping size the same, gave a $50 \%$ reduction in power requirements, while maintaining the Gaussian distribution but increasing the beam size gave a $31 \%$ power reduction.

There are a number of potential benefits that derive from the laser power reductions:

- Reduced beam power potentially allows the same process to be carried out with a lower power laser system [32].
Since laser power and equipment cost go together, this potentially makes the system cheaper.

- Reduced beam power translates directly to reduced electricity usage and therefore reduced energy costs.

- Reduced electricity usage improves the carbon footprint of the system, making it more environmentally friendly. This is an increasingly important factor to consider in current manufacturing systems, given global decarbonisation goals.

There are two omissions which limit the accuracy of the conduction simulations with respect to experiments, which must be borne in mind when evaluating them:

- Firstly, wire-to-substrate secondary reflection was ignored. In the $1.25 \mathrm{~mm}$ Gaussian experiments, this phenomenon could have initiated the wire-substrate interface melting which the simulations did not predict.

- Secondly, wire melting and subsequent fluid flow were omitted from consideration. This would be expected to have a major effect on predictions of wire to substrate heat
Table 2 Substrate heating power savings

\begin{tabular}{llll}
\hline & $\begin{array}{l}1.25 \mathrm{~mm} \\
\text { Gaussian beam }\end{array}$ & $\begin{array}{l}1.25 \mathrm{~mm} \text { pedestal } \\
\text { beam }\end{array}$ & $\begin{array}{l}3.5 \mathrm{~mm} \text { Gaussian } \\
\text { beam }\end{array}$ \\
\hline Beam width $(\mathrm{mm})$ & 1.25 & 1.25 & 3.5 \\
Power density $\left(\mathrm{W} / \mathrm{mm}^{\wedge} 2\right)$ & 480 & 190 & 42 \\
Beam area $\left(\mathrm{mm}^{2}\right)$ & 1.227 & 1.563 & 9.621 \\
Beam power $(\mathrm{W})$ & 589 & 297 & 404 \\
Percentage overall power reduction $(\mathrm{W})$ & & $-50 \%$ & $-31 \%$ \\
\hline
\end{tabular}


transfer since the interface between the wire and substrate would be significantly altered. In addition, changes in topsurface shape and reflectivity due to the formation of the melt pool would also affect heat input into the clad track, as well as heat loss into the substrate.

Additionally, fluid flow characteristics are strongly driven by Marangoni convection [33], which is itself strongly influenced by incident energy density and its distribution within the laser beam. If melting was to be accounted for, the different beam shapes studied simulated here would also predict different convection patterns, with reduced Marangoni convection leading to reduced penetration, altering the way in which the melt pool mixes with the substrate. Differences in melt pool formation are indeed visible in Figs. 14 and 15, which show the impact of laser beam power density and beam profile on clad track shape, via their effects on fluid flow.

Alterations in mixing behaviour would then lead to alterations in microstructure, since research has also shown a close link between laser thermal control and microstructural development [30]. For example, excess dilution can alter the phase of the material, such as facecentred cubic (FCC) stainless steel-clad tracks becoming body-centred cubic (BCC) due to excess mixing with the mild steel substrate. In addition, dilution also affects grain sizes and diversities of orientation angles. Control of laser beam thermal profiles also offers the potential to control these factors.

Further development of simulations is required in order to account for these phenomena, which will then allow simulations to predict the interaction between the direct substrate heating studied here and other heat transfer mechanisms, such as liquid convection, present in the process. Use of COMSOL modules such as "Metal Processing" gives potential for the implementation of dilution and phase change prediction. This will then give an improved picture of the overall role of substrate heating in the laser-wire DED process. This will then connect the work completed here directly with previous melt pool modelling [34].

The work completed here acts to fill a gap identified in wire cladding literature, where the majority of research has focussed on general melt pool behaviour, primarily by Kim and Peng $[11,12]$ in their publications and further developed by Zhao et al. (2003). As with Pinkerton [20], the majority of modelling has focussed on powder flow processes, with relatively little attention paid to modelling the mechanics of wire-based processes. This work has served to address one feature of these processes, by studying the effects of substrate heating in wire-based DED specifically. When compared to Pinkerton [20], this work fits in the gap between material feed modelling (limited in that paper to power feed) and melt pool modelling, showing how the heating profile just before melting will affect the melting behaviour.

\section{Conclusions}

The following conclusions have been drawn from this research:

- Multiple heat fluxes can be simulated simultaneously to give an overall picture of a single laser beam. This allows the model to account for differences in material reflectivity and geometry, where geometrical differences themselves also affect reflectivity.

- Directly heating the substrate strongly affects wire temperature gradients. Key variables are the ratio between the laser beam and wire diameters and the laser beam power distribution.

- The internal wire temperature gradient is also governed by other variables like the wire reflectivity profile, the laser beam energy distribution and the relationship between them.

- Temperature profiles along the wire are a function of the wire geometry, laser beam diameter and the level of substrate heating.

- Beam size and geometry have significant effects on the temperature of the substrate. A pedestal beam heats the substrate more effectively than a Gaussian beam of the same width, while a larger Gaussian beam is also more effective in substrate heating than a smaller one. A $1.25 \mathrm{~mm}$ pedestal beam improves wetting over a samediameter Gaussian beam, while its uniform profile avoids the over-penetration that occurs with the larger Gaussian beam.

- Effective substrate heating allows deposited tracks to be created at much lower power densities and at significantly lower overall beam power levels. Lower laser beam power levels equate directly to reduced electrical energy use, which would be expected to both reduce running costs and help to improve the sustainability characteristics of the process, such as carbon footprint, which is an increasingly important factor in manufacturing.

- Optimisation of the laser profiles is needed to create fully wetted tracks with minimal mixing of the wire and substrate metals. The modelling and experimental results presented here demonstrate the need for more in-depth knowledge of the process to allow a better predictive module to be created.

- The level of mixing of the wire and substrates drastically alters the microstructure of the deposited tracks, with Fig. 15 and Fig. 16 showing the microstructural difference between different penetration levels where clad tracks have similar top surface profiles. There is therefore a direct link 
between laser beam profiles and substrate heating on one side, and microstructural results on the other.

\section{Appendix}

The beam was positioned using the variables given in Table 3 .

Table 3 Model parameters

\begin{tabular}{llll}
\hline Name & Units & Quantity & Parameter description \\
\hline 1_sub & $\mathrm{mm}$ & 35 & Substrate length \\
W_sub & $\mathrm{mm}$ & 15 & Substrate width \\
t_sub & $\mathrm{mm}$ & 0. & Substrate thickness \\
r_beam & $\mathrm{mm}$ & 0.625 & Laser beam radius \\
r_wire & $\mathrm{mm}$ & 0.5 & Wire radius \\
s_abs & & 0.22 & Substrate normal \\
P_laser & $\mathrm{W}$ & 550 & absorptivity [35] \\
\hline
\end{tabular}

Beam positioning variables are given in Table 4.

Table 4 Variables for beam positioning

\begin{tabular}{lll}
\hline Name & Quantity & Description \\
\hline x0 & $0 \mathrm{~mm}$ & $X$-axis position of beam centre \\
y0 & $1.6[\mathrm{~mm} / \mathrm{s}]^{*} \mathrm{ss}$ & $\begin{array}{r}Y \text {-axis position of beam centre, } \\
\text { with respect to time, traverse } \\
\text { rate }=1.6 \mathrm{~mm} / \mathrm{s}\end{array}$ \\
& & $\begin{array}{l}\text { Time-based position modifier, } \\
\text { with } 4 \mathrm{~s} \text { start delay }\end{array}$ \\
& if $(\mathrm{t}<=4,0, \mathrm{t}-4)$ &
\end{tabular}

Acknowledgements The authors acknowledge the assistance of Mark Capers and David Britton, Optical Engineering technicians who greatly assisted with the carrying out of practical experiments.

Author contribution Author contributions were as follows:

- Nicholas Goffin: conceptualisation, methodology, software, validation, formal analysis, investigation, writing - original draft, writing review and editing, visualisation

- John Tyrer: resources, writing - review and editing, supervision, project administration, funding acquisition

- Lewis Jones: writing - review and editing

- Rebecca Higginson: resources, writing - review and editing, supervision, project administration

Funding The Engineering and Physical Sciences Research Council (EPSRC) has funded this research via a research studentship grant. They had no role in the investigation beyond that.
Availability of data and material The model used to create the simulations has been uploaded to the Loughborough Research Repository DOI: $10.17028 /$ rd.lboro.12867032

\section{Declarations}

Ethical approvals No ethical approvals were required for this research.

Consent to publish All authors have consented to publication.

Conflict of interest The authors declare no competing interests.

Open Access This article is licensed under a Creative Commons Attribution 4.0 International License, which permits use, sharing, adaptation, distribution and reproduction in any medium or format, as long as you give appropriate credit to the original author(s) and the source, provide a link to the Creative Commons licence, and indicate if changes were made. The images or other third party material in this article are included in the article's Creative Commons licence, unless indicated otherwise in a credit line to the material. If material is not included in the article's Creative Commons licence and your intended use is not permitted by statutory regulation or exceeds the permitted use, you will need to obtain permission directly from the copyright holder. To view a copy of this licence, visit http://creativecommons.org/licenses/by/4.0/.

\section{References}

1. Mahmood K, Stevens N, Pinkerton AJ (Sep. 2012) Laser clad corrosion protection for mild and harsh environments. Surf Eng 28(8): 576-584

2. Capello E, Colombo D, Previtali B (May 2005) Repairing of sintered tools using laser cladding by wire. J Mater Process Technol 164-165:990-1000

3. Miranda RM, Lopes G, Quintino L, Rodrigues JP, Williams S (Dec. 2008) Rapid prototyping with high power fiber lasers. Mater Des 29(10):2072-2075

4. Francois MM, Sun A, King WE, Henson NJ, Tourret D, Bronkhorst CA, Carlson NN, Newman CK, Haut T, Bakosi J, Gibbs JW, Livescu V, Vander Wiel SA, Clarke AJ, Schraad MW, Blacker T, Lim H, Rodgers T, Owen S, Abdeljawad F, Madison J, Anderson AT, Fattebert JL, Ferencz RM, Hodge NE, Khairallah SA, Walton O (Aug. 2017) Modeling of additive manufacturing processes for metals: challenges and opportunities. Curr Opin Solid State Mater Sci 21(4):198-206

5. Alizadeh-Sh M, Marashi SPH, Ranjbarnodeh E, Shoja-Razavi R, Oliveira JP (2020) Dissimilar laser cladding of Inconel 718 powder on A-286 substrate: microstructural evolution. J Laser Appl 022048(32): 9

6. Alizadeh-Sh M, Marashi SPH, Ranjbarnodeh E, Shoja-Razavi R, Oliveira JP (2020) Prediction of solidification cracking by an empirical-statistical analysis for laser cladding of Inconel 718 powder on a non-weldable substrate. Opt Laser Technol 128(March): 106244

7. Goldak J, Chakravarti A, Bibby M (1984) A new finite element model for welding heat sources. J Mater Process Technol 299 15(June):305

8. Nunes A Jr (1983) An extended Rosenthal weld model. Weld J 62(6): $165-170$

9. Limmaneevichitr C, Kou S (2000) Experiments to simulate effect of Marangoni convection on weld pool shape. Weld Res Suppl 9: 231-237 
10. Picasso M, Hoadley A (1994) Finite element simulation of laser surface treatments including convection in the melt pool. International Journal of Numerical Methods for Heat and Fluid Flow 4(1):61-83

11. Kim J, Peng Y (2000) Melt pool shape and dilution of laser cladding with wire feeding. J Mater Process Technol 104(3):284-293

12. Kim J, Peng Y (2000) Time-dependent FEM simulation of dilution control of laser cladding by adaptive mesh method. KSME Int J 14(2):177-187

13. Zhao G, Cho C, Kim J-D (May 2003) Application of 3-D finite element method using Lagrangian formulation to dilution control in laser cladding process. Int J Mech Sci 45(5):777-796

14. Cho C, Zhao G, Kwak S-Y, Kim CB (Nov. 2004) Computational mechanics of laser cladding process. J Mater Process Technol 153154:494-500

15. Wei S, Wang G, Shin YC, Rong Y (2018) Comprehensive modeling of transport phenomena in laser hot-wire deposition process. Int J Heat Mass Transf 125:1356-1368

16. Toyserkani E, Khajepour A, Corbin S (2004) 3-D finite element modeling of laser cladding by powder injection: effects of laser pulse shaping on the process. Opt Lasers Eng 41(6):849-867

17. Tseng W, Aoh J (Jun. 2013) Simulation study on laser cladding on preplaced powder layer with a tailored laser heat source. Opt Laser Technol 48:141-152

18. Roehling TT, Wu SSQ, Khairallah SA, Roehling JD, Soezeri SS, Crumb MF, Matthews MJ (Apr. 2017) Modulating laser intensity profile ellipticity for microstructural control during metal additive manufacturing. Acta Mater 128:197-206

19. Bertini L, Bucchi F, Frendo F, Moda M, Monelli BD (2019) Residual stress prediction in selective laser melting. Int $\mathrm{J}$ Adv Manuf Technol 105(1-4):609-636

20. Pinkerton $\mathrm{AJ}$ (2015) Advances in the modeling of laser direct metal deposition. J Laser Appl 27(S1):S15001

21. Li J, Li HN, Liao Z, Axinte D (2021) Analytical modelling of full single-track profile in wire-fed laser cladding. J Mater Process Technol 290(April 2020):116978

22. $\mathrm{Gu} \mathrm{H}, \mathrm{Li} \mathrm{L}$ (2019) Computational fluid dynamic simulation of gravity and pressure effects in laser metal deposition for potential additive manufacturing in space. Int J Heat Mass Transf 140:51-65

23. Chua BL, Ahn DG, Kim JG (2019) Influences of deposition strategies on thermo-mechanical characteristics of a multilayer part deposited by a wire feeding type DED process. J Mech Sci Technol 33(12):5615-5622

24. Yadav HNS, Kumar M, Kumar A, Das M (2021) COMSOL simulation of microwave plasma polishing on different surfaces. Mater Today Proc. https://doi.org/10.1016/j.matpr.2021.01.266

25. Vajdi M, Sadegh Moghanlou F, Sharifianjazi F, Shahedi Asl M, Shokouhimehr M (2020) A review on the Comsol Multiphysics studies of heat transfer in advanced ceramics. J Compos Compd 2(1):35-44

26. Goffin NJ, Higginson RL, Tyrer JR (2015) The use of Holographic Optical Elements (HOE's) to investigate the use of a flat irradiance profile in the control of heat absorption in wire-fed laser cladding. J Mater Process Technol 220:191-201

27. Modest MF (2001) Reflectivity and absorptivity of opaque surfaces. In: Ready JF, Farson DF (eds) LIA handbook of laser materials processing, 1st edn, pp 175-181

28. Boyden SB, Zhang Y (2006) Temperature and wavelengthdependent spectral absorptivities of metallic materials in the infrared.pdf. J Thermophys Heat Transf 20(1):9-15

29. Ya W, Pathiraj B, Liu S (2016) 2D modelling of clad geometry and resulting thermal cycles during laser cladding. J Mater Process Technol 230:217-232

30. Tyrer JR, Noden SC (1996) Diffractive optical elements for manipulation of high power $\mathrm{CO} 2$ laser radiation - a feasibility study. Lasers, Optics, and Vision for Productivity in Manufacturing I 2789

31. Kell J, Tyrer JR, Higginson RL, Jones JC, Noden S (2011) Laser weld pool management through diffractive holographic optics. Mater Sci Technol 28(3):354-363

32. Goffin N, Jones LCR, Tyrer J, Ouyang J, Mativenga P, Woolley E (2020) Characterisation of laser system power draws in materials processing. J Manuf Mater Process 4(2):48-65

33. Fotovvati B, Wayne SF, Lewis G, Asadi E (2018) A review on melt-pool characteristics in laser welding of metals. Adv Mater Sci Eng 2018:18

34. Dal M, Fabbro R (2016) [INVITED] An overview of the state of art in laser welding simulation. Opt Laser Technol 78:2-14

35. Xie J, Kar A (1999) Laser welding of thin sheet steel with surface oxidation. Weld J 78(10):343-348

Publisher's note Springer Nature remains neutral with regard to jurisdictional claims in published maps and institutional affiliations. 